\title{
The Impact of Supply-Chain and Quality Management Procedures on the Innovation Performance of Small and Medium Enterprises
}

\author{
Ameneh Farah Kordmahaleh ${ }^{1 *}$ and Hossein Farah Kordmahaleh ${ }^{2}$
}

${ }^{1}$ Master of Industry-Systems Engineering, Tehran, Iran. ${ }^{2}$ Chief Manager of Virtual Education, Shahid Beheshti University, Tehran, Iran.

\section{*Corresponding Author: \\ $\rtimes$ farahkordmahale@gmail.com}

Received: 15 December, 2020

Accepted: 15 January, 2021

Published: 30 January, 2021

\begin{abstract}
Small and medium-sized organizations are considered as the engine of economic development and employment. The share of small and medium-sized organizations for more than $95 \%$ of businesses is creating $50 \%$ of value added worldwide and depending on the country, production between $60 \%$ to $90 \%$ of all new jobs. The present paper, with examining the information obtained from 73 small, medium-sized manufacturing enterprises, studied the relationship between information sharing in the supply chain and innovation performance of the organization by considering factors such as quality management and supplierspecific investment. In this study, 4 main hypotheses regarding the relationship between chain information sharing, supply of quality management, supplierspecific investment, and the effect of relationship between quality management and supplier-specific investment on innovation performance of the organization have been examined. The results of the study indicated that information sharing in the supply chain has a positive and direct effect on quality management and supplier-specific investment. The results also showed that the impact of information sharing in the supply chain on the specific investment of the supplier is higher than its impact on quality management. Finally, the impact of quality management on organizational innovation performance is far greater than the impact of supplier-specific investment on organizational innovation performance.
\end{abstract}

Keywords: Supply chain, Supply chain information sharing, Quality management, Supplier specific investment, Innovation performance, Small and medium enterprises

\section{Introduction}

The share of small and medium-sized organizations for more than $95 \%$ of businesses is creating $50 \%$ of value added worldwide and depending on the country, and production between $60 \%$ to $90 \%$ of all new jobs [1]. Accordingly, for many years now, governments and the academic community have played a prominent role in the national economy due to the prominent and growing role of small and medium-sized organizations, as well as the irreplaceable role of these organizations compared to big ones with regard to approaches such as stimulating economic growth and increasing competition in industry, increasing industrial innovation, increasing government tax revenue, creating employment opportunities, and attracting surplus labor, special attention has been paid to the maintenance and development of these organizations [2].

In fact, small and medium-sized organizations have been considered as the engine of economic development and employment. In Germany, for example, these organizations play a vital role by creating job opportunities and participating in GDP, to the extent that these organizations account for $99 \%$ of the total organizations and $31 \%$ of the country's industrial production [3].

Small businesses are able to respond quickly to market demand, organizationally flexible, and have more effective internal communication and greater growth than the large organizations, however the small and medium-sized organizations always have some 
problems. Researches have indicated that the problems in the development process of these organizations are much greater than those of large organizations, which in turn leads to gradual, slow development and ultimately accelerates the death of these organizations. Accordingly, the life cycle of these organizations is shorter. In the United States, for example, 68\% of small to medium-sized organizations have a lifespan of only 5 years, $19 \%$ have a lifespan of 6 to 10 years, and only $13 \%$ have a lifespan of more than 10 years [4].

Accordingly, in recent years, the issue of sustainable development and increasing the life cycle of small and medium-sized enterprises has received much attention from researchers and experts [5]. One of the trends that has received much attention in recent research, is the study of innovation performance as an appropriate measure of achieving sustainable development in today's competitive and turbulent environment [6]. In this regard, important components such as supply chain information sharing (as one of the main pillars in organizational information sharing) and quality management (as one of the key foundations of lean systems that have an undeniable impact on enterprise sustainability) are more important than the other topics $[2,7]$. The present study attempts to develop a model to examine the impact of supply chain information sharing and quality management on the performance of innovation at the level of small and medium enterprises by combining previous concepts in the research literature.

\section{Theoretical Foundations of Research}

\section{Supply-chain information sharing}

In today's business environment, the competitive approach has shifted from individual competitiveness of organizations to competition on supply chains [8]. Today's organizations have realized that effective competition and controlling organizational costs depends on the organization's focus on capabilities, skills, as well as resources throughout the supply chain [9]. In this regard, effective supply chain has become increasingly important due to its ability to maintain competitive advantage as well as improve organizational performance [10]. The origin of the concept of supply chain has been inspired by various fields such as 1) quality revolution, 2) concepts related to materials and logistics integrated management, 3) growing markets and industrial networks, 4) concepts related to increasing market concentration, and 5) studies on industry [11]. According to Banerjee and Mishra [12], understanding and implementing supply chain management practices for the organization plays a key role in maintaining a competitive position and promoting profitability in the market. Therefore, the concept and procedures related to supply chain management have been highly regarded by business managers, consultants, as well as academic researchers [1].

As competition in global markets intensifies, many enterprises are increasingly using effective supply chain practices [13], which include the $=$ supply chain information and supplier-specific investment.

The concept of supply chain information sharing has been extensively explored in the last decade $[14,15]$. In a study done by Zhou and Benton [16], information sharing includes three aspects: information sharing support technology, information content, and information quality. Here, the sharing of supply chain information refers to the exchange of quality information, price information, technical information and the other information related to production and operation between manufacturers and suppliers. The exchange of information between manufacturers and suppliers can help enterprises reduce the bullwhip effect of the supply chain and better respond to uncertainties in the foreign trade environment [13]. Sharing information among supply chain members enables them to practice internal / external operations. For SMEs, supply chain information sharing becomes more important because SMEs are more dependent on suppliers than large enterprises. Sharing information with their suppliers can help small and medium-sized enterprises integrate with their suppliers, which is important for these enterprises to achieve social sustainability [2]. Receiving information (e.g., price information and technical information) from their suppliers allows small to medium-sized organizations to better plan their production and capacity.

Supplier-specific investment means measuring the output of investors on specific tools and equipment in order to communicate with suppliers, as well as measuring the degree to which manufacturers adapt their production system to align with supplier products [1]. Existence of specific supplier investment leads to close interaction, mutual commitment and loyalty. According to transaction cost theory, the more specialized the commodity needed, usually the closer the relationship between supplier and buyer. Sharing supply chain information provides the basis for improving business processes. Other reasons for manufacturers to make special suppliers' investments include expanding knowledge and increasing reputation [17]. For example, some manufacturers do not want their top suppliers to outsource their competitors and therefore invest equal shares in their suppliers. This can lead to downtime and delays in processes and projects. Therefore, sharing information in the supply chain by increasing the level of trust will reduce any delay and stop in the supply chain. Accordingly, the hypotheses can be presented as follows:

Hypothesis 1: Information sharing in the supply chain has a positive and direct relationship with quality management. 
Hypothesis 2: Information sharing in the supply chain has a positive and direct relationship with the specific investment of the supplier.

\section{Innovation performance}

In today's world, the ability to adapt and manage change is the key to the success and survival of any organization, and acquiring these capabilities requires the organization to pay attention to the creativity and innovation of individuals. Successful organizations are those whose creativity is driven by innovation. In other words, if today's organizations want to be alive, they must be dynamic and their managers and employees must be creative and innovative people to be able to adapt the organization to these developments and meet the needs of society. It can be said that in the global economic system and increasing competition, creativity and innovation are the key to survival and organizational success [18]. Innovation has increasingly become one of the key factors for enterprises' longterm success in competitive markets; because enterprises with high innovation capacity will be able to respond to environmental challenges more quickly and better. Therefore, innovation plays an important role in creating value and gaining a competitive advantage [19]. In the business world, increasing global competition and increasing customer demand have led organizations to seek continuous improvement, increased flexibility and increased quality. Quality has now become the key to gain a competitive advantage. Higher quality reduces costs and increases productivity, followed by increasing market share and better competitiveness of organizations (Fili et al., 1398). Kim et al. (2012) investigated the relationship between quality management and innovation. The results showed that there was a significant relationship between quality management and innovation and quality management affects the types of innovation in the organization. Hong et al. [19] also noted in their study that quality management in the supply chain has a positive effect on the performance of organizational innovation.

Special investment provides a close relationship between seller and buyer. In this way, suppliers can participate in the early stages of their buyers' new product development process, which helps reduce new product or service development time. When manufacturers invest in specific tools and equipment in their suppliers, the commonality of production tools and equipment increases, which reduces errors in new product design because a common increase reduces the number of parts used in new product design. Since supplier-specific investment tends to reduce transaction costs and material unit costs from suppliers, a close supplier-buyer relationship is likely to reduce the cost of developing a new product for manufacturers. Accordingly, the hypotheses can be presented as follows:

Hypothesis 3: Quality management has a positive and direct relationship with organizational innovation performance.

Hypothesis 4: Supplier-specific investment has a positive and direct relationship with the organization's innovation performance. The conceptual model of the research is presented in the figure below.

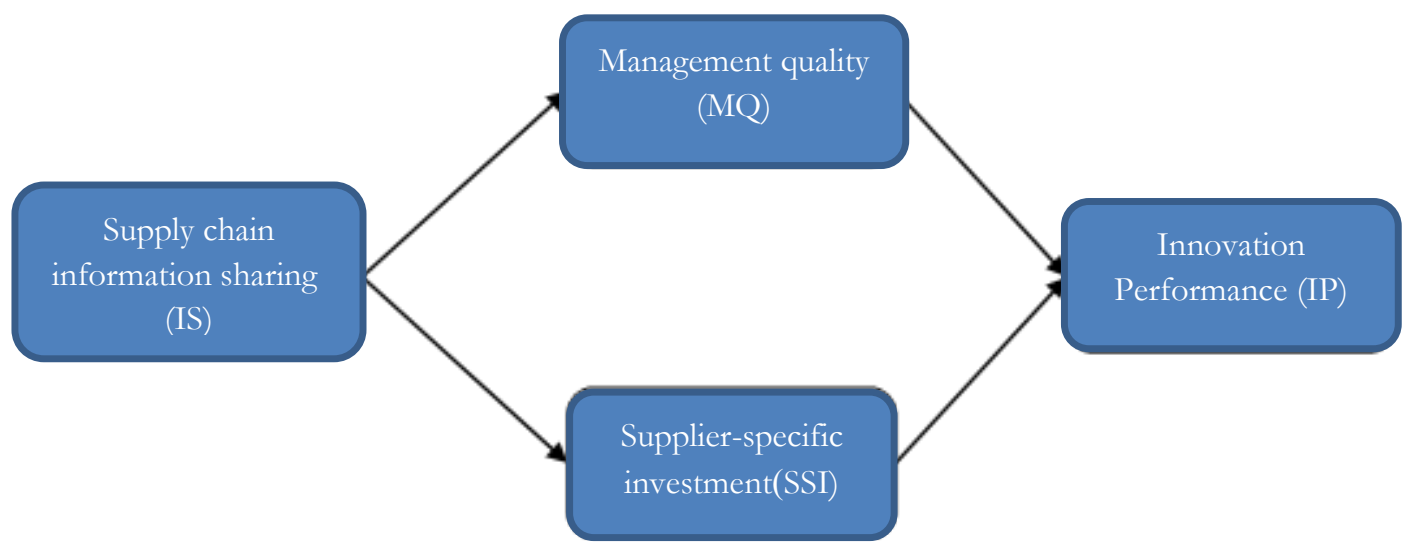

Figure 1. Conceptual model of research.

\section{Method}

A questionnaire consisting of 12 questions was prepared for the respondents to express their agreement or disagreement (from 1 to 5) for each question. Content validity and face validity methods were used to assess validity. Considering that the research questionnaire is a standard questionnaire extracted from the subject literature, the content validity of the questionnaire is supply. Regarding face validity, a team of 5 experts, three of whom had academic and research experience, and two with more than five years of experience in the field of supply chain and quality management, reviewed the questionnaire and made some remarks. They made suggestions on how to ask questions, the layout and 
length. The Cronbach's alpha index was used to measure reliability, the results of which are presented in the next section.

The statistical population of this study includes CEOs, supervisors and department managers of manufacturing enterprises. According to what has been presented about small and medium enterprises in Iran, organizations with less than 150 employees are among the small and medium enterprises. According to the survey and considering the list of small and medium enterprises provided by the Ministry of Silence, data were collected and communication with organizations was done. A total of 221 enterprises were counted from the relevant list and this number was the basis for sending the questionnaire. After 2 consecutive times in one-week intervals, 73 questionnaires were received in full form, which shows an acceptable return rate of $33 \%$.

\section{Model evaluation method}

Model evaluation is performed at two levels of measurement model and structural model, each of which is described separately. In this research, it has been used the approach proposed by Hanafizadeh and Zare [20] using SmartPLS software. That is, in the first stage, using the method of partial least squares analysis, the model for measuring the relationships between factors and dimensions is investigated and in the second stage, using the method of partial least squares analysis, the structural model of relationships between dimensions of the model is investigated. These steps are described below.

One of the statistics through which the researcher is able to determine the suitability of the data for analysis is the KMO test, the value always fluctuates between 0 and 1 (Hair et al., 1995). If the KMO value is less than 0.50 , the data will not be suitable for factor analysis. If the value is between 0.50 and 0.69 , factor analysis can be done with more caution. However, if the value is greater than 0.7 , the correlations between the data will be suitable for factor analysis. This value is estimated 0.862 for research data which is in the appropriate range.

\section{Method of evaluation of measurement models}

The first factor that should be considered in the evaluation of measurement models is the onedimensionality of the model indices. This means that each index in the set of indices must be loaded with a large value of factor impact, only to one dimension or latent variable. For this purpose, the value of factor impact must be greater than 0.60 . It should be noted that the value of factor impact is less than 0.40 and should be removed from the set of indices. This is done manually by removing indices that have an operating load of less than 0.40 [21].
Cronbach's alpha coefficient is another factor that can be used to assess the internal consistency reliability of measurement models. The value of this coefficient varies from 0 to 1 ; values above 0.70 are accepted and values below 0.60 are considered undesirable [22].

The value of composite reliability (CR) is another factor that can be used to assess the internal consistency reliability of measurement models. The value of this coefficient varies from 0 to 1 ; values above 0.70 are accepted and values less than 0.60 are considered undesirable [21].

Convergence validity shows the high correlation of indices of one structure in comparison with the correlation of indices of the other structures, which should be evaluated in measurement models. AVE (average variance extracted) is used to assess convergence validity in SmartPLS software. The value of this coefficient also varies from 0 to 1 , and values higher than 0.50 are accepted [23].

Diagnostic validity indicates the existence of minor correlations between the indices of a structure and the indices of other structures that should be evaluated in measurement models. To assess this type of validity, the Fornell-Larcker criterion is used [23]. The FornellLarcker criterion refers to the fact that the second root of the average variance extracted (AVE) of each structure is greater than the correlation values of that structure with the other structures.

\section{Structural model evaluation method}

After evaluating the measurement models, it is time to evaluate the structural model. The first key criterion used for this purpose is determination coefficient R2. The determination coefficient R2 measures the relationship between the amount of variance described in a latent variable and the total value of variance. The value of this coefficient also varies from 0 to 1 , which values are more desirable. China (1988) considers values close to 0.67 to be desirable, ones close to 0.33 to be normal, and ones close to 0.190 to be weak.

The next step in evaluating structural models is to evaluate the path coefficients between the variables embedded in the model. At this stage, the researcher must examine the algebraic sign of the coefficient, its size and its level of significance. Paths whose coefficient signs are opposite to the expected direction of the hypothesis, will not confirm the hypothesis. The size of the path coefficient indicates the strength of the relationship between two latent variables. Some researchers believe that a path coefficient greater than 0.100 indicates a certain value of impact on the model [24]. In addition, path coefficients must be significant at a level of at least 0.05 .

\section{Model analysis}

Assessment model analysis 
The loading results of the latent dimension indices in the model are presented in the table below. If an index has a factor impact of less than 0.4 , it needs to be removed from the index list. Due to the fact that in the table below, all indices have a factor impact greater than 0.4 , there is no need to delete any of them, and with the same set of indices, we go to the next step. This indicates that the metrics and questions in the research questionnaire measure their respective dimensions well and are in fact good metrics for evaluation.

Table 1

Load values of latent dimension

indices in the model.

\begin{tabular}{lllll}
\hline & QM & IS & SSI & IP \\
\hline QM1 & 0.83 & & & \\
QM2 & 0.86 & & & \\
QM3 & 0.81 & & & \\
\hline IS1 & & 0.92 & & \\
IS2 & & 0.93 & & \\
IS3 & & 0.89 & & \\
\hline SSI1 & & & 0.88 & \\
SSI2 & & & 0.93 & \\
SSI3 & & & 0.90 & \\
\hline IP1 & & & & 0.91 \\
IP2 & & & & 0.89 \\
IP3 & & & & 0.87 \\
\hline
\end{tabular}

As mentioned, it is necessary to remove indices with an impact factor less than 0.4. However, considering that all the indices of the model have an impact factor greater than 0.4 , there is no need to delete the variables and move on to the next step. At this stage, it is necessary to report the Cronbach's alpha coefficients, structural reliability and AVE, the information of which is as follows. As it can be observed from this table, all values for the said coefficients are at an acceptable level. This means that Cronbach's alpha coefficients of structural reliability for all dimensions of the model is greater than 0.7 and the value of AVE for all of them is greater than 0.5 . The determination coefficient R2 measures the relationship between the value of variance described in a latent variable and the total value of variance. The value of this coefficient also varies from 0 to 1 , which larger values are more desirable. China (1988) considers values close to 0.67 to be desirable, ones close to 0.33 to be normal, and ones close to 0.90 to be weak.

Table 2

Cronbach's alpha coefficients, structural reliability, R2 and AVE in the model.

\begin{tabular}{lccc}
\hline & Average variance extracted & Composite reliability & Cronbach's alpha \\
\hline QM & 0.65 & 0.84 & 0.77 \\
IS & 0.53 & 0.90 & 0.89 \\
SSI & 0.71 & 0.93 & 0.84 \\
IP & 0.69 & 0.89 & 0.79 \\
\hline
\end{tabular}

The next step is to evaluate the diagnostic validity of the model. As mentioned earlier, the Fornell-Larcker criterion is used for this purpose, according to which the second root of the average variance extracted (AVE) of each structure is greater than the correlation values of that structure with other structures. As it can be observed, all the values on the main diameter of the table are larger than the values below, which means that the diagnostic validity of the model is supplied.

Table 3

Diagnostic validity of structures for the model.

\begin{tabular}{lcccc}
\hline & QM & IS & SSI & IP \\
\hline QM & 0.71 & & & \\
IS & 0.4 & 0.7 & & \\
SSI & 0.3 & 0.21 & 0.72 & \\
IP & 0.3 & 0.2 & 0.2 & 0.82 \\
\hline
\end{tabular}


Note: The elements of the original diameter are the square of the values of variance described in each structure and the elements of the non-original diameter are the values of the correlation between the structures. For diagnostic validity, diagonal elements must be larger than non-diagonal elements.

\section{Structural model analysis}

After evaluating the measurement models, it is time to evaluate the structural model. At this stage, the researcher must examine the algebraic sign of the coefficient, its size and its level of significance. The size of path coefficient indicates the strength of the relationship between two latent variables. Some researchers believe that the path coefficient greater than 0.100 indicates a certain value of impact on the model. The obtained results for path coefficients and their significance level are presented in the following figures. If the values of $t$ are greater than 1.96, its significance level is 0.05 . Also, for values of tgreater than 2.576 and 3.29 , the significance levels are equal to 0.01 and 0.001 , respectively.

Table 4

Results of structural model study.

\begin{tabular}{lcccc}
\hline & Path coefficient & t test & Significance level & Result \\
\hline IS -> QM & 0.56 & 8.60 & 0.001 & Confirmed relationship \\
IS -> SSI & 0.70 & 12.91 & 0.001 & Confirmed relationship \\
QM -> IP & 0.66 & 12.05 & 0.05 & Confirmed relationship \\
SSI -> IP & 0.24 & 2.30 & 0.001 & Confirmed relationship \\
\hline
\end{tabular}

As it can be seen from the table, all path coefficients related to the relationships formulated in the model are significant at the level of at least 0.05 . Also, according to the results of data analysis, the role of perceived compatibility variable in the relationship between the independent variable and the dependent variables of the model is well visible.

\section{Conclusion and Recommendations}

The purpose of this study was to investigate the relationship between supply chain information sharing and innovation performance of the organization by considering components such as quality management and supplier-specific investment. In this regard, a model based on research literature and specifically based on a study done by Zhou and Lee [2] was designed. In this research, four main hypotheses and the conceptual model of the research were presented accordingly. The statistical population of this study includes CEOs, supervisors and department managers of manufacturing enterprises. According to the survey and considering the list of small and medium enterprises provided by the Ministry of Silence, data were collected and communication with organizations was done. A total of 221 enterprises were counted from the relevant list and this number was the basis for sending the questionnaire. Among all the total questionnaires sent, 73 ones were received in full form, which showed an acceptable return rate of $33 \%$. Finally, the same number of questionnaires received, was the basis of statistical analysis of the research. The results of the study indicated the fact that supply chain information sharing had a positive and direct effect on quality management and supplier-specific investment. Also, the innovation performance of the organization was affected by the quality management and the supplier-specific investment.

This study was very valuable because the body of research that has been done on supply chain information sharing, quality management and supplierspecific investment in the performance of organizations, especially small and medium-sized enterprises, was limited. The results indicated that information sharing in the supply chain plays an important role in supply chain management. In other words, supply chain information sharing can be an effective basis for improving the level of quality management and supplier-specific investment, therefore the use of information technology to facilitate and improve the level of information sharing should be highly considered by managers and officials. This is important in small and medium-sized enterprises, which usually pay less attention to the IT sector and the use of new technologies due to lack of resources. This result should be considered and managers should understand that the focus on the use of IT is not a cost but an appropriate investment to improve the services of the organization.

This study also showed that quality management and supplier-specific investment had a positive effect on innovation performance. Innovation, which has become a very important topic in today's business world, has attracted the focus of many organizations. On the one hand, large enterprises usually have more resources and more flexibility to develop new products. Therefore, it is important for small and medium-sized enterprises to find ways to compete with large enterprises in the field of innovation. The results of this research for experts suggest that small and mediumsized enterprises can strengthen their quality management practices and strengthen the specific 
investment of their suppliers to improve their innovation performance.

\section{References}

1. Lee Y, Shin J, Park Y. The changing pattern of SME's innovativeness through business model globalization. Technol Forecast Soc Change, 2012; 79(5): 832-842.

2. Zhou H, Li L. The impact of supply chain practices and quality management on firm performance: Evidence from China's small and medium manufacturing enterprises. Int J Prod Econ. 2020; 107816.

3. Sousa Jabbour A, Ndubisi NO, Seles B. Sustainable development in Asian manufacturing SMEs: progress and directions. Int J Prod Econ. 2020; 225.

4. Xiao C, Yu C, Yue M. Life cycle of small and medium-sized enterprises based on external environmental perspective. Empirical Research that Takes 5 Metropolises Including Shenzhen as Samples. Systems Engineering. Theor Pract. 2009; 29(1).

5. Shou Y, Shao J, Lai K-h, Kang M, Park Y. The impact of sustainability and operations orientations on sustainable supply management and the triple bottom line. J Clean Prod. 2019; 240: 1-13.

6. Wu L, Subramanian N, Abdulrahman M, Liu C, Lai $\mathrm{K}-\mathrm{h}$, Pawar K. The impact of integrated practices of lean, green, and social management systems on firm sustainability performance-evidence from Chinese fashion auto-parts suppliers. Sustain. 2015; 7: 38383858.

7. Teixeira C, Lopes I, Figueiredo M. Classification methodology for spare parts management combining maintenance and logistics perspectives. J Manag Analyt. 2018; 5(2): 116-135.

8. Lambert DM, Cooper MC. Issues in supply chain management. Indust Market Manag. 2000; 29(1): 65-83.

9. Mohammaddust F, Rezapour S, Farahani RZ, Mofidfar M, Hill A. Developing lean and responsive supply chains: A robust model for alternative risk mitigation strategies in supply chain designs. Int J Prod Econ. 2017; 183: 632-653.

10. Sangari MS, Hosnavi R, Zahedi MR. The impact of knowledge management processes on supply chain performance: An empirical study. Int J Logist Manag. 2015; 26(3): 603-626.
11. Chen IJ, Paulraj A. Towards a theory of supply chain management: the constructs and measurements. $J$ Operat Manag. 2004; 22(2): 119-150.

12. Banerjee M, Mishra M. Retail supply chain management practices in India: A business intelligence perspective. J Retailing Consum Serv. 2015.

13. Bicocchi N, Cabri G, Mandreoli F, Mecella M. Dynamic digital factories for agile supply chains: an architectural approach. J Indust Inform Integrat. 2019; 15: 111-121.

14. Zhou L, Chong A, Ngai E. Supply chain management in the era of the internet of things. Int $J$ Prod Econ. 2015; 159: 1-3.

15. Wong C, Lai K, Bernroider E. The performance of contingencies of supply chain information integration: the roles of product and market complexity. Int J Prod Econ. 2015; 165: 1-11.

16. Zhou H, Benton WC. Supply chain practice and information sharing. J Oper Manag. 2007; 25: 1348-1365. 17. Kang M, Mahoney J, Tan D. Why firms make unilateral investments specific to other firms: the case of OEM suppliers. Strat Manag J. 2009; 30: 117-135.

18. Deloitte. Rising Innovation in China. China Innovation Ecosystem Development Report. Deloitte, China. 2019.

19. Hong J, Liao Y, Zhang Y, Yu Z. The effect of supply chain quality management practices and capabilities on operational and innovation performance: evidence from Chinese manufacturers. Int J Prod Econ. 2019; 212: 227-235.

20. Hanafizadeh P, Zare Roasan A. Method of analyzing multilevel structures using smartpls software. First Edition. Termeh Publishing. 2012.

21. Gefen DD, Straub A. Practical guide to factorial validity using PLS-Graph: Tutorial and annotated example. Communications of the AIS. 2005; 16: 91109.

22. Cronbach L. Coefficient alpha and the internal structure of tests. Psychometrika, 1951; 16(3): 297-334.

23. Fornell C, Larcker D. Evaluating structural equation models with unobservable variables and measurement error. J Market Res. 1981; 18(1): 39-50.

24. Huber F, Herrmann A, Frederik M, Vogel J, Vollhardt K. Kausalmodellierung mit Partial Least Squares- Eine anwendungsorientierte Einführung. Wiesbaden: Gabler. 2007.

\section{SJAMAO}

Copyright: (C) 2021 The Author(s); This is an open-access article distributed under the terms of the Creative Commons Attribution License (http://creativecommons.org/licenses/by/4.0), which permits unrestricted use, distribution, and reproduction in any medium, provided the original work is properly cited.

Citation: Farah Kordmahalehl A, Farah Kordmahaleh H. The Impact of Supply-Chain and Quality Management Procedures on the Innovation Performance of Small and Medium Enterprises. SJAMAO, 2021; 3(1): 9-15. 